Norbert Meuter · Narrative Identität 


\section{Norbert Meuter}

\section{Narrative Identität}

Das Problem der personalen Identität im Anschluß an Emst Tugendhat, Niklas Luhmann und Paul Ricoeur 
Gedruckt mit Hilfe der Geschwister Boehringer Ingelheim Stiftung für Geisteswissenschaften in Ingelheim am Rhein

Die Deutsche Bibliothek - CIP-Einheitsaufnahme

\section{Meuter, Norbert:}

Narrative Identität : das Problem der personalen Identität im Anschluß an Emst Tugendhat, Niklas Luhmann und Paul Ricoeur / Norbert Meuter. - Stuttgart : $M$ und $P$, Verl. für Wiss. und Forschung, 1995

Zugl.: Düsseldorf, Univ. Diss., 1993

ISBN 978-3-476-45133-0

ISBN 978-3-476-45133-0

ISBN 978-3-476-04229-3 (eBook)

DOI $10.1007 / 978-3-476-04229-3$

Dieses Werk ist einschließlich aller seiner Teile geschützt. Jede Verwertung außerhalb der engen Grenzen des Urheberrechtsgesetzes ist ohne Zustimmung des Verlages unzulässig und strafbar. Das gilt insbesondere für Vervielfältigungen, Übersetzungen, Mikroverfilmungen und Einspeichenung in elektronischen Systemen.

M \& $\mathbf{P}$ Verlag für Wissenschaft und Forschung ein Verlag der J.B. Metzlerschen Verlagsbuchhandlung und Carl Emst Poeschel Verlag GmbH in Stuttgart

C 1995 Springer-Verlag GmbH Deutschland Ursprünglich erschienen bei J.B. Metzlersche Verlagsbuchhandlung und Carl Ernst Poeschel Verlag GmbH in Stuttgart 1995 


\section{Vorwort}

Die nachfolgende Untersuchung zum Identitätsproblem ist von der Philosophischen Fakultät der Heinrich-Heine-Universität Düssseldorf im Januar 1994 als Dissertation angenommen worden. Für die fortlaufende Unterstützung sowie für zahlreiche inhaltliche Anregungen möchte ich mich an dieser Stelle bei Prof. Dr. Oswald Schwemmer bedanken, der die Arbeit als Doktorvater betreut hat. Mein Dank gilt auch dem weiteren Gutachter Prof. Dr. Herbert Anton. Für die Durchsicht des Manuskriptes bedanke ich mich bei Prof. Dr. Manfred Stöckler, PD Dr. John Michael Krois, Georg Schiller und Dr. Ingo Rill, der mir zudem durch zahlreiche Gepräche sehr geholfen hat. Die notwendige Konzentration auf die Arbeit hat mir das Cusanuswerk durch ein Graduiertenstipendium ermöglicht. Schließlich bedanke ich mich auch bei Annette Spickhoff für jegliche sonstige Ünterstützung. Widmen möchte ich die Arbeit meiner Mutter und dem Andenken meines Vaters. 


\section{Inhaltsverzeichnis}

$\begin{array}{ll}\text { Einleitung } & 9\end{array}$

Teil 1 Identität

1.1 Die sprachliche Bezugnahme auf raumzeitliche Identitäten:

Ernst Tugendhat $\quad 14$

1.2 Die Selbstorganisation sinnhafter Identitäten: Niklas Luhmann 26

1.2.1 Einführende Überlegungen/Zum Systembegriff 26

1.2.2 Sinn (I) - Bestimmung des Phänomens 43

1.2.2.1 Sinn als Intention eines Subjekts?

1.2.2.2 Sinn als Einordnung in einen Kontext? 48

1.2.2.3 Universalität von Sinn $\quad 52$

1.2.2.4 Die sinnkonstituierende Differenz aktuell/potentiell 55

1.2.2.5 Sinn als Funktionsbegriff 64

1.2.3 Sinn (II) - Die Genese sinnhafter Ordnung 68

1.2.3.1 Beobachten (Unterscheiden und Bezeichnen) 68

1.2.3.2 Wiederholen (Kondensieren und Konfirmieren) 77

1.2.3.3 Identität und Symbolisierung $\quad 83$

$\begin{array}{lll}\text { 1.2.3.4 Lebenswelt } & 95\end{array}$

1.2.4 Sinn (III) - Prozeß und Struktur $\quad 98$

$\begin{array}{ll}\text { 1.2.4.1 Reversibilität/Irreversibilität } & 100\end{array}$

$\begin{array}{lll}\text { 1.2.4.2 Prozeßgeschichte } & 103\end{array}$

$\begin{array}{ll}\text { 1.2.4.3 Episodenbildung } & 109\end{array}$

1.3 Die Ausbildung narrativer Identitäten: Paul Ricoeur 122

1.3.1 Einführende Überlegungen/Theorie der dreifachen mimesis

1.3.2 Mimesis-II: Narrativität als 'Synthesis des Heterogenen' $\quad 128$

1.3.3 Mimesis-I: die pränarrative Struktur der Lebenswelt $\quad 139$

1.3.3.1 Pränarrativität und Handeln: David Carr 148

1.3.3.2 Gibt es 'unerzăhlte Geschichten'?

Louis Mink vs. Alasdair MacIntyre 158

1.3.4 Mimesis-III: Rezeption als 'integrierender Bestandteil' der mimetischen Tätigkeit 
Teil 2 Personale Identität

2.1 Personale Identität als rationale Selbstbestimmung 176

2.1.1 Das deiktische Personalpronomen 'ich' 179

2.1.2 Praktisch-reflektiertes Sichzusichverhalten 183

2.2 Personale Identität als Konstruktion sozialer Systeme 200

2.2.1 Psychische Systeme/Soziale Systeme 200

2.2.2 Doppelte Kontingenz 211

2.2.3 Der Begriff 'Mensch' 215

2.2.4 Personale Identität und Individualität 221

2.3 Personale Identität als narrative Identität 245

$\begin{array}{ll}\text { 2.3.1 Poiesis/Dynamik } & 247\end{array}$

2.3.2 Anfang/Ende $\quad 250$

2.3.3 Teleologische Struktur/Autorschaft 253

$\begin{array}{ll}\text { 2.3.5 Charakter/Stil } & 260\end{array}$

$\begin{array}{ll}\text { Schluß } & 265\end{array}$

$\begin{array}{ll}\text { Literatur } & 268\end{array}$ 